\title{
PELUANG INVESTASI USAHA BUDIDAYA KUTU LAK (Laccifer lacca Kerr): STUDI KASUS DI KPH PROBOLINGGO PERUM PERHUTANI UNIT II JAWA TIMUR
}

\author{
Investment Opportunity Laccifer Lacca KERR Cultivation Business: Case Study at KPH Probolinggo \\ Perum Perhutani Unit II East Java.
}

Ira Taskirawati, F. Gunawan Suratmo, Dudung Darusman, dan Noor Farikhah Haneda

\begin{abstract}
Lac insect (Laccifer lacca Kerr) is phytophogus insect, that feed on Kesambi Tree (Schleichera oleosa Merr). During its life cycle, lac insect has been producing secretion in liquid form, known as LAK and having many uses, such as varnish/polish, food cover, drug capsule, cassette ribbon, etc. In 2005, Perum Perhutani has produced $60.547 \mathrm{~kg}$ LAK pellets, but has not fulfilled yet market demand. Cultivation technique is still conducted in a very sampling, and easy to be studied. Investment in developing lac insect is also profitable, and promising. There are two choices of management schemes in it cultivate, the first is by infecting lac insect to the host tree when the tree is 15 years old (project I) and the second is by infecting lac insect when the tree is 4 years old (project I). Financially, the Project II is more beneficial than Project I, so that the investment for project II is reasonable to be done. The value of NPV+22.321.052.395, IRR $16.9 \%$, BCR 1.55 and Net B/C 3.71 with discounted payback period for 10 year 8 months.
\end{abstract}

Key words: Laccifer lacca Kerr, Schleichera oleosa Merr, investment opportunity, strategy in developing

\section{PENDAHULUAN}

Lak termasuk dalam kelompok resin yang diperoleh dari hasil sekresi insekta Laccifer lacca Kerr (kutu Lak) yang hidup pada tanaman inangnya. Hasil sekresi tersebut mengelilingi tubuh kutu lak yang kemudian mengeras dan berfungsi sebagai pelindung dari ancaman musuh alami dan lingkungan yang tidak menguntungkan bagi kehidupan kutu lak. Tanaman inang kutu lak adalah tanaman Kesambi (Schleicera oleosa Merr.), Plosa (Butea sp.), Jamuju (Coscuta australis), Widoro/Kaliandra (Zizyphos jujuba), Acacia villosa, dan A. arabica. Di Indonesia, tanaman kesambi merupakan tanaman yang diprioritaskan untuk digunakan sebagai tanaman inang dalam budidaya kutu lak.

Menurut Kalshoven (1981), kutu lak telah di import dari India pada tahun 1936 dan kemudian dikembangkan di Bogor dengan $A$. famesiana, $A$ villosa, dan beberapa tanaman kehutanan lainnya sebagai inang. Khususnya di Pulau Jawa, budidaya kutu lak dikembangkan di Banyukerto, Probolinggo, Jawa Timur sejak tahun 1963 oleh Perum Perhutani. Pada tahun 1986, budidaya kutu lak juga mulai dikembangkan di Kabupaten Alor dan saat ini budidaya kutu lak sudah tersebar secara merata di Nusa Tenggara Timur dan Nusa Tenggara Barat.

Awalnya, pemanfaatan lak hanya sebatas sebagai bahan pelitur, bahan segel pengaman surat berharga, pita kaset dan bahan isolasi. Saat ini, lak mempunyai kegunaan yang lebih luas lagi diantaranya sebagai bahan kosmetik, zat aditif makanan, bahan semi konduktor dan sebagai bahan kulit kapsul obat.

Lak merupakan salah satu komoditi hasil hutan non kayu yang sangat potensial sebagai salah satu sumber penghasil devisa negara. India, Thailand, dan Cina merupakan negara-negara penghasil lak di dunia selain Indonesia yang merupakan pesaing dalam merebut pangsa pasar lak. Permintaan pasar dunia akan produk lak, dari tahun ke tahun terus meningkat. Pada tahun 1998 sebanyak 20 ton lak butiran diekspor dari NTT ke Amerika Serikat dan itu hanya memenuhi $4 \%$ dari permintaan impor Amerika Serikat yaitu sebanyak 500 ton lak butiran (Wibowo 2003). Produksi lak Banyukerto sejak tahun 1982 mencapai kisaran produksi 1000 ton dan pada tahun 1990 mencapai puncak produksi yaitu sebesar 1700 ton. Sejak tahun 1991, produksi lak di Banyukerto mengalami penurunan produksi dan pada tahun 1993 dan 1994 masing-masing hanya 330 ton dan 148 ton. 
Penurunan produksi tersebut disebabkan oleh adanya serangan parasit (Wibowo 2003).

Tingginya permintaan pasar menjadikan budidaya kutu lak memiliki prospek yang sangat baik untuk dikembangkan. Tulisan ini memberikan informasi mengenai peluang investasi usaha budidaya kutu lak, hal ini dimaksudkan agar dapat dijadikan motivasi untuk lebih mengembangkan budidaya kutu lak di Indonesia sehingga nantinya dapat dijadikan sebagai salah satu sumber pendapatan bagi masyarakat yang ada di sekitar hutan.

\section{BAHAN DAN METODE}

\section{Tempat dan Waktu Penelitian}

Penelitian dilakukan di wilayah kerja Kesatuan Pemangkuan Hutan (KPH) Probolinggo, Perum Perhutani Unit II Jawa Timur. Waktu pengumpulan data adalah antara bulan Agustus sampai dengan September 2005.

\section{Pengumpulan Data}

Data yang dikumpulkan terdiri atas data primer dan sekunder. Data primer didapatkan melalui survei lapangan dan wawancara dengan menggunakan kuesioner. Responden dipilih secara sengaja (purposive), yaitu pemilihan responden yang dimaksudkan untuk mendapatkan informasi yang diperlukan dalam penelitian ini. Responden terdiri atas Administratur KPH Probolinggo, Divisi Pemasaran, Divisi SDM, Divisi Produksi, Karyawan dan Masyarakat sekitar wilayah kerja KPH Probolinggo.

Data sekunder yang merupakan pelengkap data primer diperoleh dari perusahaan, Dinas Kehutanan, dan Instansi yang terkait serta literaturliteratur yang mendukung.

\section{Analisis Data}

Data dianalisis dalam dua tahap. Tahap pertama menganalisis data pada kondisi sekarang dan tahap kedua menganalisis data pada kondisi perubahan. Analisis dilakukan terhadap aspek-aspek di dalam studi kelayakan proyek, yaitu : (1) Aspek Pasar dan Pemasaran (2) Aspek Teknik dan Teknologi, (3) Aspek Manajemen Operasional (4) Aspek Finansial, dan (5) Aspek Lingkungan.

Ada 2 macam proyek budidaya lak yang dilaksanakan: pada proyek pertama tanaman kesambi baru ditulari setelah berumur 15 tahun, hal ini juga dilakukan oleh Perum Perhutani dan pada proyek kedua sistem budidaya kutu yang mengalami modifikasi, pada proyek ini penularan kutu lak sudah dilakukan sejak tanaman berumur 4 tahun. Pabrik sudah berdiri sejak tahun pertama pengusahaan dan agar pabrik sudah dapat berproduksi maka perusahaan akan membeli bahan lak dari petani yang membudidayakan kutu lak untuk menutupi produksi sampai tahun ke-14 untuk proyek I dan sampai dengan tahun ke-9 untuk proyek II.

Kriteria kelayakan investasi menggunakan beberapa indikator kelayakan secara finansial, yaitu Net Present Value (NPV), Internal Rate of Return (IRR), Net Benefit -Cost Ratio (Net B/C), Profil Indeks atau B/C ratio dan Discounted Pay Back Period (PBP).

\section{HASIL DAN PEMBAHASAN}

Perum Perhutani memproduksi seedlak untuk memenuhi kebutuhan lak di dalam dan luar negeri. Untuk pasaran dalam negeri, lak dikirim ke Surabaya, Solo, Semarang, dan Bandung. Untuk pasaran luar negeri, lak dikirim ke India, Pakistan dan Jepang. Harga jual lak butiran yang dipasarkan oleh Perum Perhutani sebesar Rp. 20.640/kg.

Berdasarkan hasil analisis pasar, permintaan terhadap seedlak baik untuk kebutuhan dalam negeri maupun untuk ekspor terus meningkat setiap tahunnya dengan harga jual yang cukup tinggi. Namun, selama ini permintaan akan lak butiran (seedlak) belum dapat dipenuhi karena produksi masih rendah yang disebabkan oleh faktor-faktor biotik yang mempengaruhi budidaya kutu lak. Jadi, berdasarkan analisis aspek pasar, maka budidaya kutu lak layak untuk dilaksanakan.

Analisis aspek teknik dan teknologi menunjukkan bahwa lokasi proyek memenuhi syarat dalam budidaya kutu lak maupun produksi lak butiran. Begitu pula dengan teknik dan teknologi yang diterapkan dalam budidaya kutu lak dan produksi lak butiran. Sehingga, berdasarkan hasil analisis aspek teknik dan teknologi, maka budidaya kutu lak layak untuk dilaksanakan.

Analisis deskripsi terhadap bentuk dan struktur organisasi, wewenang dan tanggung jawab, spesifikasi tenaga kerja dan kebutuhan biaya gaji dan upah tenaga kerja menunjukkan hasil analisis aspek manajemen operasional untuk budidaya kutu lak layak untuk dilaksanakan. Begitu 
Table 1. Finansial Analysis of Laccifer lacca Kerr. Cultivation at 10 percent discount for 4.000 ha

\begin{tabular}{llrr}
\hline & \multicolumn{1}{c}{ Uraian } & \multicolumn{1}{c}{ Proyek I } & Proyek II \\
\hline 1. & Net Present Value (NVP) & (-) Rp. 198.604.120,- & Rp. 22.321.052.395,-- \\
2. & Internal Rate of Return (IRR) & $9,87 \%$ & $16,9 \%$ \\
3. & Net Benefit - Cost Ratio (Net B/C) & 0,98 & 3,71 \\
4. & Benefit - Cost Ratio (BCR) & 1 & 1,55 \\
5. & Discounted Payback Periode (PBP) & 20 tahun 9 bulan & 10 tahun 8 bulan \\
\hline
\end{tabular}

pula halnya dengan analisis lingkungan, hasil analisis lingkungan menunjukkan proyek ini layak untuk dijalankan.

Analisis finansial budidaya kutu lak pada tingkat diskonto $10 \%$ untuk luasan sebesar 4000 ha ditunjukkan pada Tabel 1.

Ada dua metode pengembangan yang dilakukan, pertama dengan melakukan penularan kutu lak pada saat tanaman berumur 15 tahun (proyek I) dan metode pengembangan yang kedua adalah dengan melakukan penularan kutu lak pada saat tanaman berumur 4 tahun (proyek II). Secara analisis finansial, proyek II lebih menguntungkan sehingga investasi pada proyek II layak untuk dilakukan dengan nilai NPV +22.321.052.395, IRR 16,9\%, Net B/C 3,71 dan BCR 1,55 dengan Discounted Payback Periode 10 tahun 8 bulan (Tabel 1).

Pada proyek ini, kemungkinan perubahan keadaan yang terjadi antara lain naiknya total biaya, turunnya total pendapatan serta ada perubahan secara bersamaan antar naiknya total biaya dan turunnya total pendapatan. Pada tabel 18 menunjukkan, perubahan terhadap kenaikan total biaya, penurunan pendapatan serta kombinasi dari keduanya menyebabkan proyek pertama tidak layak untuk dilaksanakan. Sebaliknya pada proyek II, adanya perubahan pada kondisi yang diujikan tidak menyebabkan bisnis ini tidak layak untuk dilaksanakan. Analisis finansial pada proyek II menunjukkan adanya perubahan antara kenaikan biaya dan penurunan harga secara bersamaan tetap membuat indikator dalam proyek ini tetap layak untuk dilaksanakan (Tabel 2.).

\section{KESIMPULAN}

Ada dua skenario usaha yang dilakukan dalam pengembangan budidaya kutu lak, skenario pertama (proyek I), tanaman kesambi baru ditulari setelah berumur 15 tahun, dan skenario kedua (proyek II) penularan kutu lak sudah dilakukan sejak tanaman berumur 4 tahun. Hasil perhitungan tersebut menunjukkan proyek II yang lebih menguntungkan sehingga lebih layak untuk melakukan investasi pada proyek ini (nilai NPV +22 321052 395, IRR 16.9\%, BCR 1.55 dan Net B/C 3.71 dengan Discounted Payback Periode 10 tahun 8 bulan).

\section{UCAPAN TERIMA KASIH}

Ucapan terima kasih kepada $\mathrm{KPH}$ Probolinggo Perum Perhutani Unit II Jawa Barat atas segala bantuan dan kerjasamanya selama pelaksanaan penelitian.

Table 2. Sensitivities Analysis of Laccifer lacca Kerr. Cultivation for 4.000 ha

\begin{tabular}{cccccc}
\hline PROYEK I & \multicolumn{5}{c}{ Jumlah } \\
\hline \multicolumn{2}{c}{ Perubahan } & NVP & IRR & Net B/C & BCR \\
\hline Total Biaya & Total Pendapatan & NV.592.868 & $0,87 \%$ & 0,06 & 0,87 \\
$+15 \%$ & - & -9.724 .806 & 0,85 \\
- & $-15 \%$ & -9.694 .802 .250 & $1.6 \%$ & 0,06 & 0,74 \\
$+15 \%$ & $-15 \%$ & -19.220 .790 .998 & $41,62 \%$ & 0,70 & \\
\hline PROYEK II & & & & & \\
\hline$+15 \%$ & - & 16.213 .034 .654 & $15,35 \%$ & 2,56 & 1,35 \\
- & $-15 \%$ & 12.864 .876 .789 & $15,05 \%$ & 2,41 & 1,32 \\
$+15 \%$ & $-15 \%$ & 6.756 .859 .036 & $12.88 \%$ & 1,60 & 1,14 \\
\hline
\end{tabular}




\section{DAFTAR BACAAN}

Adjidarna. 1990. Pengusahaan Lak Perhutani di Banyukerto. Duta Rimba No. 125-126/XVI : 38-42. Jakarta.

Anisah, L.N. 2001. Upaya Peningkatan Kualitas dan Rendemen Produk Lak di Pabrik Banyukerto KPH Probolinggo Unit II Jawa Timur. PT. Perhutani (Persero).

Borror, D.J, C.A. Triplehorn, and N.F. Johson. 1996. Pengenalan Serangga. Gajah Mada University Press. Yogyakarta.

[BSN] Badan Standarisasi Nasional. 2000. SNI 01-5009.2-2000: Lak Butiran (seed lak). Jakarta.

David. 1997. Strategic Management $6^{\text {th }}$. Prentice Hall. New Jersey.

Ghermandi, E. 2003. Lasifer Laka - Laccifer Lacca - Cocus Lacca - Laksha. Http://www.easygrowing.org/documents/EG -LasiferLaka.doc, [27 Januari 2005]

Gittinger, J.P. 1986. Economic Analysis of Agricultural Projects. Second Edition, Completely, Revised and Expanded. The John Hopkins University Press. Baltimore and London.

Gray, C., P. Simanjuntak, L.K. Sabur, P.F.L. Maspaitella, dan R.C.G. Varley. 1997. Pengantar Evaluasi Proyek. Edisi Kedua. PT. Gramedia Pustaka Utama. Jakarta.

Heyne, K. 1987. Tumbuhan Berguna Indonesia IV. Penelitian dan Pengembangan Kehutanan, Departemen Kehutanan. Jakarta.

Husnan, S. dan Suwarsono. 1997. Studi Kelayakan Proyek. Cetakan ke-2. UPPM AMP YKPN. Yogyakarta.

Intari, S.E. 1980. Laccifer lacca Kerr.: Serangga Penghasil Bahan Lak. Lembaga Penelitian Hutan. Bogor.

Jauch, G. 1999. Manajemen Stategi dan Kebijakan Perusahaan. Erlangga. Jakarta.

Kalshoven, L.G.E. 1981. The Pests of Crops in Indonesia. Alih Bahasa: Laan PA van der. PT. Ichtiar Baru - van Hoeve. Jakarta.

Margunadi. 1994. Materi Kursus Kilat Kader Mandor Teknik Kultur Lak. BKPH Taman
KPH Probolinggo Perum Perhutani Unit II Jawa Timur. Probolinggo.

Mulyana, A.D, dan S.E. Intari. 1995. Jenis Pohon Inang Alternatif Kutu Lak di BKPH Taman dan Sukapura KPH Probolinggo Jawa Timur. Duta Rimba No. 185186/XX/1995:15-18. Jakarta.

Pearce dan Robinson. 1997. Manajemen Strategi: Formulasi, Implementasi dan Pengendalian. Binarupa Aksara. Jakarta.

Perum Perhutani. 1987. Pedoman Pengusahaan Klas Perusahaan Lak. Perum Perhutani. Jakarta.

Perum Perhutani Unit II Jawa Timur. 1994. Laporan Hasil Pelaksanaan Studi Banding Pengusahaan Lak di Pulau Alor. KPH Probolinggo Perum Perhutani Unit II Jawa Timur. Probolinggo.

Perum Perhutani Unit II Jawa Timur. 2004. Buku Saku: Pengelolaan Tanaman Inang Kesambi dan Kultur Lak dan Pengelolaan Lak Cabang Menjadi Seedlak. KPH Probolinggo Perum Perhutani Unit II Jawa Timur. Probolinggo.

Rangkuti F. 2000. Analisis SWOT: Teknik Membedah Kasus Bisnis. PT Gramedia. Jakarta.

Setiadi, D. Dan T.E. Komar. 2001. Prospek Pengembangan Kutu Lak di Alor, Nusa Tenggara Timur. Duta Rimba No. 258/XXV:29-31. Jakarta.

Sumantri, I. 1992. Perbaikan Sistem Pemungutan Lak Dalam Rangka Peningkatan Produksi. Jurnal Penelitian Hasil Hutan, 10(2): 63 68.

Sutojo, S. 1993. Studi Kelayakan Proyek: Teori dan Praktek. PT. Pustaka Binaman Pressindo. Jakarta.

Umar, H. 1997. Studi Kelayakan Bisnis: Manajemen, Metode dan Kasus. PT. Gramedia Pustaka Utama. Jakarta.

Wibowo, L.R. 2003. Produk Lak NTT: Mampu Menembus Amerika. Majalah Kehutanan Indonesia, Edisi I/2003. 
Diterima : 14 Desember 2007

Ira Taskirawati

Lab. Keteknikan dan Diversifikasi Hasil Hutan

Fakultas Kehutanan Universitas Hasanuddin

J. Perintis Kemerdekaan Km. 10 Tamalanrea, Makassar 90245

Email: tasqira@yahoo.com

F. Gunawan Suratmo, Dudung Darusman, dan Noor Farikhah Haneda Fakultas Kehutanan Institut Pertanian Bogor

Kampus IPB Darmaga Bogor 16680 